\title{
Reform and Exploration of Single Chip Computer Course Teaching Experiment Board
}

\author{
ZHANG Fu-yan TENG Ying-yan \\ Department of Computer Science and Technology, Dalian Neusoft University of Infor- \\ mation, Dalian, 116023, China
}

\begin{abstract}
This paper analyses the limitations and shortcomings of existing single chip computer course teaching experiment equipment. For the conveniences of students to learn and use, enhancing students' comprehensive ability and quality, the author designed a teaching experiment board. The teaching board has been used in the process of teaching practice, with good teaching results.
\end{abstract}

Keywords: Single Chip Computer Course, Teaching Experiment Board, Teaching Practice

\section{Introduction}

Single chip computer course aims to teach the basic knowledge of single chip computer principles, the development processes and development methodology, etc., training students' software development and hardware circuit analysis, system design and debug capabilities. The course features focus on practice and operation based on the theory.

Many colleges and universities in the practical single chip computer course generally use purchased sets of integrated single chip experiment boxes. Although in the market, many experiment boxes can be chosen, in the application process, almost all have some disadvantages. Ex- periment box supporting data are incomplete or not detailed enough. In circuit wiring, even many key chips are hidden under the panel, if failure to use, difficult to detect and repair, can only be returned to the manufacturer. Although experiment box resource rich, limited reserved ports lead to very difficult to accomplish more integrated experiments, and lack of flexibility as well. And the volume is usually larger, not easy to carry, can only be used in the laboratory for the students. If the experiment is not completed in accordance with the prescribed time, it has only to give up, of course, more inconvenient to after-class independent experiment box exploratory research and experimentation.

The author teaches at a university in China. The university is IT applicationoriented university. In this university, personnel training targets innovative spirit and practical ability "practical, international, personalized" high-quality, highlevel expertise. For this teaching purpose, concerning the above shortcomings, the author self-developed a single-chip board based on years of teaching experience. The experiment board is rich in resources, easy to expand, flexible to operate, easy to carry, and to meet the teaching needs, fits perfectly with the teaching content, and suitable for beginners. 


\section{Experiment Board Designing Scheme}

\subsection{Basic Resources}

The experiment board can support two series of 51 single chip computers, AT89S51 and STC89C51, in which ISP download cable port program can be used at AT89S51, serial port at STC89C51.

The experiment board is designed as modularized, the hardware structure diagram shown in Fig. 1.

\begin{tabular}{|c|c|c|c|}
\hline Buzzer & $\begin{array}{c}6 \text { eight digital } \\
\text { tube }\end{array}$ & $4 * 4$ matrix keyboar & \\
\hline $\begin{array}{l}\text { 8-bit light- } \\
\text { emitting diodes }\end{array}$ & DIP switch & \multicolumn{2}{|c|}{$\begin{array}{c}\text { Button \& light-emitting } \\
\text { diodes }\end{array}$} \\
\hline Serial port & $\begin{array}{l}\text { Simple I/O input } \\
\text { expansion module }\end{array}$ & \multirow{2}{*}{\multicolumn{2}{|c|}{ Single chip computer }} \\
\hline SIPO module & $\begin{array}{l}\text { Simple I/O output } \\
\text { expansion module }\end{array}$ & & \\
\hline $\begin{array}{l}\text { ISP download } \\
\text { cable port }\end{array}$ & $\begin{array}{c}\text { Temperature } \\
\text { detection } \\
\text { module }\end{array}$ & $\begin{array}{c}\text { System bus } \\
\text { extension module }\end{array}$ & \multirow{5}{*}{ 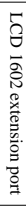 } \\
\hline Reset circuit & System & RAM & \\
\hline USB power & expansion port & extension (6264) & \\
\hline port & \multirow{2}{*}{$\begin{array}{c}\text { Programmable } \\
\text { parallel port } \\
\text { extension }(8255)\end{array}$} & \multirow{2}{*}{$\begin{array}{c}\text { Analog-to-digital } \\
\text { conversion } \\
\text { ADC0809 }\end{array}$} & \\
\hline Relay & & & \\
\hline
\end{tabular}

Fig. 1: Experiment board hardware structure diagram.

The buzzer is driven by PNP transistors. 6 eight digital tubes are common anode digital tubes, designed with dynamic circuit, choice of drive ends with a PNP transistor. With RS-232C protocol standard 9-pin serial port, the EIA and TTL level is conversed by chip MAX3232. SIPO modules use chip CD4094 data serial input to the conversion of the 8-bit parallel output. Two relays use the darlington circuit chip ULN2003, highvoltage and high-current, as driver chip. Simple I/O output expansion modules and input expansion modules use latch chips 74LS373 and 74LS244 respectively. The core of temperature detection module is a single bus interface digital temperature sensor chip DS18B20, in which the data line pins a $4.7 \mathrm{~K}$ pull-up resistor. At single chip computer system bus expansion modules, the 74LS373 latch single chip computer address signals are used. 3-8 decoding 74LS138, or gate 74LS32 and not gate 74LS04 design address decoding circuit are used to divide memory 6264, programmable parallel port chip 8255, analog-to-digital conversion chip ADC0809 and simple I/O modules address ranges.

\subsection{Resource Port Design}

Except power line and ground lead, each resource module is almost completely independent. Each module ports are reserved and welding the pin. Resources modules at experiment need to be connected by experimenters. The ports reserved at experiment board are the following.

- Function Port. Each resource module designs programmable control pin ports as reserved, e.g. All 4 single chip computer module $\mathrm{I} / \mathrm{O}$ ports are reserved. Matrix keyboard rows, columns control ends also are reserved. Before the matrix keyboard programming control, any port of P1, P2 and P3 shall be connected matrix keyboard using the dupont line. In order to make control more flexible, there are enough ports at some modules hardware designed. As A/D converter module ADC0809 for example, ADC0809 digital output pins, address pins, allow output pin, conversion end instructions pin and clock signal input pin, all are reserved. The conversion pin START is connected with address latch pin ALE as a read operation pin reserved. While programming using ADC0809, either reserved three bus ports of the single chip computer system expansion respectively, or make it with the single chip computer I/O port directly connected. So the students 
can program in two completely different ways of control, so as to more deeply understand and master the principles and methods of the single chip computer system control.

- System expansion reserved port. If the experiment board hardware resources can not meet the application requirements, the extended application of circuit board is needed. So, enough expansion ports are designed, including: power, I/O port, three single chip computer expansion bus lines, address decoding circuit chip select signal, and so on.

- Single chip computer pin multiplexes between few modules. For example, both 9-pin serial port and SIPO modules require the use of single chip computer serial data to transmit-receive pin RXD and TXD. Jumper modes are designed to solve the problem of pin conflict of, at which, resource module and the corresponding single chip computer pin are cut out by jumper.

\section{Experiment Board Application in Teaching}

At the beginning of the course, each student is given a blank experiment board, who can enter into the lab welding the experiment board. Teachers give students programming image files of test circuit board resource modules. In this process, the students can be familiar with the hardware structure of the experiment board, cognitive components, practice welding skills, and can master the basic hardware circuit debugging methods.

While the circuit board welding is completed and debugged in the teaching process, students are required to carry a laptop and an experiment board. After teachers finish teaching the basic princi- ples, programming control mode and project examples of the course unit, students are arranged to use the circuit board to do a series of experiment projects.

With the advancement of teaching, students gradually complete a series of experiment projects. Guided by teachers, students step by step integrate of the experiment projects completed. By the end of the course, students are required to achieve "multi-functional electronic clock" project hardware architecture and software control. The project features include: either time display at eight digital tube or on the LCD, either time can be set via serial communication or set by button, beeper buzzer alarm clock time, external interrupt button to select the display time, temperature or voltage value. Fig. 2 shows the hardware structure of the multifunctional electronic clock, by which can be seen the structural integrity. Students can master the knowledge and ability of the single chip computer system application development through the integrated project practices.

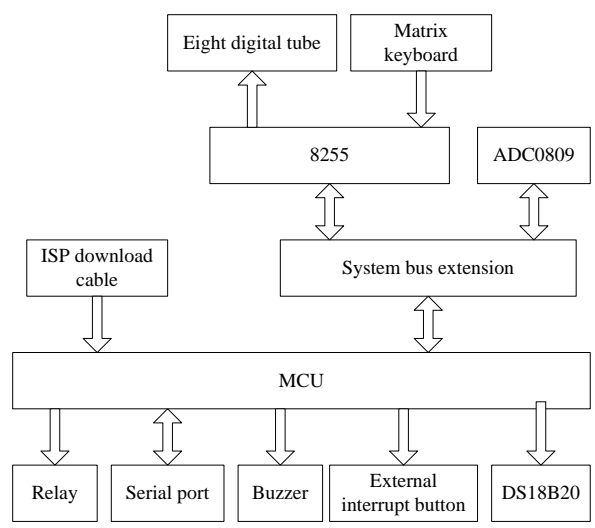

Fig. 2: Multifunction electronic clock hardware structure diagram 


\section{Conclusions}

The experiment board specially designed for teaching fits perfectly with the teaching content. Its volume is smaller and easy to carry. After teachers finish theoretical content or examples, students can use it at class, observe the operating results of visual images to validate and summarize the content, truly "learning to do, learning by doing", Theory is combined with practice perfectly, greatly stimulating interest in learning. The circuit is simple, reserved ports are rich, flexible to connect, easy for beginners to use and study. The circuit board used in single chip computer practice teaching, with good teaching, not only can train the student software programming skills, but also enhance its hands-on and practical ability, with single chip computer engineering practice ability and attainment for system application development needs.

\section{References}

[1] Song Yun-pu, Zhou wen-yong, Xu Ming-qian, Liu Gang, Zhou Mengwei, "Exploration on the Ways and Facilities of Single-chip Computer Experiment in Universities", Re- search and Exploration in Laboratory, Vol. 28, No.11, Nov. 2009, pp. 6-9.

[2] Wu Song, Zhang Yan-hui, "Reform and Exploration of Single -Chip Computer Experiment Teaching in University", J. Da Zhong Ke Ji, No. 11, Nov. 2011, pp.194-205.

[3] Hui Huang, Lai Xiao-chen, Chi Zongzheng, Wu Yi-qi, "Exploration of homemade node of teaching experiment equipment based on single-chip computer in colleges and universities", Experiment Technology and Management, Vol. 29, No.5, May. 2012, pp.229-232.

[4] Xie Wei-cheng, "Principle and Application of MCU \& C Programming", Tsinghua University Press, 2009, pp.143-146.

[5] Yao Zhi-guang, "Experiment and Explore in Course of Single-Chip computer Teaching", Journal of Shanxi Economic Management Institute, Vol. 18, No.2, Jun. 2010, pp. 111-113.

[6] Jia Ping, Ding Xiang-rong, Hu Meilan, "Design and Application of Testing Platform for single chip computer Teaching of Union of Teaching, Learning and Doing", Experiment Technology and Management, Vol. 29, No.6, Jun. 2012, pp. 139-142. 